Journal of Futures Markets

\title{
Derivatives Pricing with Liquidity Risk
}

\begin{tabular}{|r|l|}
\hline Journal: & Journal of Futures Markets \\
\hline Manuscript ID & Futures-18-6249.R1 \\
\hline Wiley - Manuscript type: & Research Article \\
\hline Key Words: & Derivative Pricing, Liquidity Factor, Futures Contracts \\
\hline \multicolumn{2}{l}{} \\
\end{tabular}

\section{SCHOLARONE ${ }^{m}$ Manuscripts}




\section{Derivatives Pricing with Liquidity Risk}

Yongmin Zhang ${ }^{1}$, Shusheng Ding ${ }^{1}$, and Meryem Duygun ${ }^{2}$

1. School of Business, Ningbo University, 818 Fenghua Road, Ningbo, China, 315000

2. Nottingham University Business School, Nottingham, NG8 1BB, UK

\section{zhangyongmin@,nbu.edu.cn}

shusheng.ding@nottingham.edu.cn

\section{Meryem.duygun@nottingham.ac.uk}

\section{Corresponding author:}

Yongmin Zhang,

Mailing Address:

School of Business, Ningbo University

818 Fenghua Road,

Ningbo, 315211

China

Tel: +86 (0) 13373870787

Email: zhangyongmin@,nbu.edu.cn

Acknowledgement:

The work is supported by Ningbo-CASS Collaborative grant NZKT201701. 


\title{
Derivatives Pricing with Liquidity Risk
}

\begin{abstract}
This paper develops a novel, general derivative pricing model which introduces a liquidity risk factor. The model variants we outline offer a sufficient degree of flexibility so as to enable the valuation of various types of derivative classes including futures, American options, and MBS options, while existing derivative models can only price liquidity risk in European derivatives. We validate the model with oil and gold futures data and compare it to a classical benchmark model void of any liquidity risk. We find that our model is significantly more accurate than the classical model for pricing both oil and gold contracts.
\end{abstract}

JEL classification: G13

Keywords: Derivative Pricing, Liquidity Risk Factor, Futures Contracts

\section{Introduction}

All securities suffer from liquidity risk. However, this particular source of risk is especially prevalent in less liquid securities, in light of the fact that price movements for less liquid securities are typically more pronounced on average. This study attempts to redress this deficiency by advancing a pricing model for derivative securities that explicitly takes liquidity risk into account.

The impact of a liquidity risk factor on asset prices has received a large degree of attention in the field of financial research. An abundance of asset pricing models incorporating an explicit liquidity factor have been developed, which have mainly focused on equity markets, including the Capital Asset Pricing Model (CAPM) with liquidity, such as Acharya and 
Pedersen (2005) and Liu (2006). By contrast, few existing studies incorporate liquidity measures developed specifically for derivative markets. Only recently a number of studies have started paying closer attention to the impact of a liquidity factor on derivative pricing, including those of Chou et al. (2011), Bongaerts et al. (2011) and Feng et al. (2014). But these models are developed only for European style derivatives with restrictive underlying asset classes such as stocks and simple-structure bonds. The primary objective of this paper is to develop a general model framework with the objective of pricing liquidity risk into various types of derivatives. These include both European- and American-style derivatives with general underlying asset classes, such as mortgages, commodities, real estate, etc. Mortgage Backed Securities (MBSs) have an embedded pre-payment American option and the price of an MBS is equal to a price of a regular coupon bond with a fixed maturity minus the price of an American option. Therefore, we argue that our newly proposed model is capable of pricing MBS products which are subject to liquidity risk.

The significance of our novel contribution to the literature can be explained from multiple perspectives. First, based on the existing literature, we set out to develop a derivative pricing model that incorporates a liquidity risk factor. The model builds on the liquidityadjusted European option pricing model of Feng et al. (2014). However, Feng et al. (2014) only utilize the estimated liquidity model parameters and not the liquidity level itself as inputs to improve the standard Black-Scholes option pricing model. Owing to this particular approach, their model is only applicable to valuing European options. Our model differentiates itself by being considerably more flexible in view of the fact that it permits the valuation of a variety of derivatives, including futures, American options and MBSs. Given that in our model the current 
level of market liquidity is taken as an input, the direct impact of this particular factor can be readily reflected in the derivative price derived from the underlying model framework. More specifically, our model can be applied to valuing derivative prices in terms of a solution to a two-dimensional system of partial differential equations, which prove flexible enough to the valuation of both European and American options.

We estimate a model of commodity futures with a liquidity factor, given that liquidity risk appears to play a non-negligible role in futures markets. Frino, Mollica, \& Webb (2014) and Webb et al (2016) show that the liquidity risk of futures contracts is driven by various factors including traders' knowledge and co-location of their servers. Marshall et al. (2011) investigate 24 commodity futures and find that all exhibit a significant liquidity risk effect on their pricing under a different set of candidate liquidity proxies. Moreover, Marshall et al. (2013) provide evidence for the existence of a distinct and common liquidity risk factor in the commodity market and that this liquidity risk factor is closely related to the underlying commodity price. Recent works of Zhang and Ding (2018) and Zhang, Ding \& Scheffel (2018) demonstrate a significant role of liquidity risk for price shocks in various commodity futures markets. In spite of our model being constructed for a variety of types of derivatives, our empirical validation strategy is based only on oil and gold futures market data, due to the significant influence they both exert on other financial markets as well as global markets in a broader sense. As argued by Melvin and Sultan (1993), oil and gold futures markets constitute two commodity futures markets of wider relevance and interest. Souček (2013) shows how both gold and oil play a crucial role in other financial markets, most notably the stock market. Gold futures market also carry implications and convey information relevant to the T-bill rate 
(Grudnitski and Osburn, 1993), as well as the foreign exchange market. More importantly, oil and gold markets are interrelated in that they exhibit sizable volatility spillover effects between each other (Ewing and Malik, 2013). As a result, we employ data from these two markets in order to attempt a comparison of our theoretical results with certain stylized empirical facts and patterns commonly encountered in the aforementioned markets, namely, oil and gold futures markets.

As indicated in Bongaerts et al. (2011), any empirical work to date on the role of liquidity in derivative pricing has been comparatively scant, especially with regards to the market for commodity futures. More recently however, two papers have empirically explored the role of liquidity risk on the broader subject of derivative pricing. Li and Zhang (2011) compare the price of warrants with identical options - but different liquidity levels - by using data from the Hong Kong Exchange from 2002-2007. They provide evidence in support of the view that the price difference between two derivatives reflects the liquidity premium of warrants over options. Mancini et al. (2013) systematically study the role of liquidity risk in the foreign exchange market and find strong liquidity effects in this market as well. Our paper also conducts an empirical analysis by comparing two estimated values from two distinct models. We show that the liquidity-adjusted (LA) model exhibits lower values compared to the nonliquidity-adjusted (NLA) model and that the estimated values are much closer to actual market values. We then proceed to test our model for both oil and gold futures markets to find that it outperforms the benchmark model, especially for the gold futures market. Based on a comparison of the mean pricing errors from the two models, the liquidity-adjusted model is capable of improving the accuracy of estimation by around $15 \%$ in the oil and $50 \%$ in gold market. We further carry out a theoretical study on liquidity and maturity coupling effects on 
futures prices. We find that, when the assets are more illiquid, futures prices are adjusted downward to a greater degree compared to standard no-arbitrage futures prices. Such adjustment appears to occur independently of spot prices for a fixed maturity. The illiquidity adjustment depends on futures maturities; if deferred futures are less liquid than nearby futures then a longer maturity implies a deeper degree of adjustment for a fixed spot liquidity level. Therefore, spot illiquidity has greater impact on long maturity futures than on short maturity products.

Our new model has important implications for policy design in regulating liquidity risks for derivative markets including both futures and option markets. Because leverage is embedded in derivative trading, any financial risk can be magnified by a substantial multiple. Therefore, financial innovations in derivatives must be carefully regulated with effective policies and mechanisms to monitor their liquidity risk and to develop and test robust pricing models with can accurately capture liquidity risk.

The remainder of the paper is structured as follows. Section 2 provides a derivation of the general two-factor liquidity-adjusted derivative pricing model. In Section 3, we set out to validate our model based on futures markets data for oil and gold and further carry out a theoretical study on the liquidity and maturity coupling effect, leaving the final section for our conclusions.

\section{A General Model for Pricing Derivatives with Liquidity Risk}

In this section, we will develop a general model framework to price liquidity risk into various types of derivatives, including futures, options and financial innovations like mortgage backed 
securities.

We establish a filtered probability space $\left(\Omega, \sum,\left\{\sum_{\mathrm{t}}\right\}_{\mathrm{t} \geq 0}, \mathrm{P}\right)$ with $0 \leq \mathrm{t} \leq \mathrm{T}$ for a fixed time, $\mathrm{T}$, where the $\mathrm{T}$ is the lifetime of the futures contract and $\mathrm{P}$ is the probability measure either statistical or empirical. Specifically, $\Omega$ is the set of all possible outcomes of the stochastic economy within the time horizon and $\sum$ is the sigma algebra on $\Omega$ (Longstaff and Schwartz, 2001). All stochastic processes involved in this study are assumed to be $\left\{\sum_{\mathrm{t}}\right\}_{\mathrm{t} \geq 0}$-adapted.

Then, the underlying asset in the benchmark model is presumed to be perfect liquid. The price of the asset is denoted as $\mathrm{S}_{\mathrm{t}}$ and the risk-free rate is denoted as $\mathrm{r}$. We also assume that the asset price follows a pure geometric Brownian Motion (GBM):

$\frac{d S_{t}}{S_{t}}=u_{s} d t+\sigma_{s} d W_{t}^{S^{\prime} P}$

where $W_{t}^{S^{\prime} P}$ is a Wiener process under $\mathrm{P}$ measure and perfect market condition.

We now introduce into the derivative pricing model a liquidity factor modeled as a stochastic process (c.f. Feng et al., 2014, on options). The illiquidity measure $\mathrm{L}_{\mathrm{t}}$, in the underlying asset market, follows a mean-reversion stochastic process:

$d L_{t}=\alpha\left(\theta-L_{t}\right) d t+\xi d W_{t}^{L, P}$

where $\alpha$ is the mean reversion speed of the asset liquidity depending on the market condition and $\theta$ is the equilibrium level of the asset liquidity, and $\xi$ is the volatility of the asset liquidity, $W_{t}^{L, P}$ is a Wiener process under P measure.

In addition, another important measure must be introduced: the sensitivity of the asset price to the level of market liquidity, which we denote by $\beta$ (Kyle, 1985; Vives, 1995; Ozsoylev and Werner, 2011; Feng et al., 2014). Because price is sensitive to liquidity, there should be a liquidity discount factor $\gamma_{t}$, which captures the influence of liquidity on asset price. It should be 
a function of market liquidity $L_{t}$ and price sensitivity $\beta$, with $\beta>0$. Brunetti and Caldarera (2006) proposed a stochastic process for $\gamma_{\mathrm{t}}$ :

$$
d \gamma_{t} / \gamma_{t}=\left(-\beta L_{t}+\frac{1}{2} \beta^{2} L_{t}^{2}\right) d t-\beta L_{t} d W_{t}^{\gamma, P}
$$

with $d W_{t}^{\gamma, P} d W_{t}^{s^{\prime}, P}=0$.

For simplicity, we assume that there is always a price that can clear the entire market. Under such market-clearing conditions, following Brunetti and Caldarera (2006), one can prove the illiquid asset price $\mathrm{S}_{\mathrm{t}}$ follows:

$$
d S_{t} / S_{t}=\left(\mu+\beta L_{t}+\frac{1}{2} \beta^{2} L_{t}^{2}\right) d t+\beta L_{t} d W_{t}^{\gamma, P}+\sigma d W_{t}^{S^{\prime}, P}
$$

For the purpose of derivative pricing, we first disaggregate the Brownian motion of the imperfect liquid asset price into two parts:

$$
\begin{aligned}
& W_{t}^{\gamma, P}=\rho W_{t}^{L, P}+\sqrt{1-\rho^{2}} W_{t}^{u, P} \\
& d W_{t}^{L, P} d W_{t}^{u, P}=0 \\
& W_{t}^{S, P}=\int_{0}^{t} \frac{\sigma}{\sqrt{\sigma^{2}+\left(1-\rho^{2}\right) \beta^{2} L_{t}^{2}}} d W_{t}^{S^{\prime}, P}+\int_{0}^{t} \frac{\beta L_{t} \sqrt{1-\rho^{2}}}{\sqrt{\sigma^{2}+\left(1-\rho^{2}\right) \beta^{2} L_{t}^{2}}} d W_{t}^{u, P}
\end{aligned}
$$

From Levy's theorem, $W_{t}^{S, P}$ is a Brownian motion under the measure of $\mathrm{P}$ and so the asset price follows:

$$
\begin{aligned}
& d S_{t} / S_{t}=\left(\mu+\beta L_{t}+\frac{1}{2} \beta^{2} L_{t}^{2}\right) d t+\sqrt{\sigma^{2}+\left(1-\rho^{2}\right) \beta^{2} L_{t}^{2}} d W_{t}^{S, P}+\rho \beta L_{t} d W_{t}^{L, P} \\
& d W_{t}^{L, P} d W_{t}^{S, P}=0
\end{aligned}
$$

All possible martingale measures can be categorized by Girsanov densities (Bingham and Kiesel, 1998). Under the Girsanov densities, we can find the appropriate risk-neutral martingale measures for option valuation with illiquidity. The equivalent martingale measures are represented by a Girsanov derivative: 
$M(T)=\frac{d Q}{d P}$

$M_{t}=\exp \left(-\int_{0}^{t} \lambda_{1}(s) d W_{t}^{S, P}-\int_{0}^{t} \lambda_{2}(s) d W_{t}^{L, P}-\frac{1}{2} \int_{0}^{t} \lambda_{1}^{2}(s) d s-\frac{1}{2} \int_{0}^{t} \lambda_{2}^{2}(s) d s\right)$

Consequently, the Brownian motions are changed under the new measure Q:

$d W_{t}^{L, Q}=d W_{t}^{L, P}+\lambda_{1} d t$

$d W_{t}^{S, Q}=d W_{t}^{S, P}+\lambda_{2} d t$

where $\lambda_{1}$ and $\lambda_{2}$ should satisfy:

$\mu+\beta L_{t}+\frac{1}{2} \beta^{2} L_{t}^{2}-r=\lambda_{1} \sqrt{\sigma^{2}+\left(1-\rho^{2}\right) \beta^{2} L_{t}^{2}}+\lambda_{2} \rho \beta L_{t}$.

Thus, the new stochastic differential equations (SDEs) become:

$$
\begin{aligned}
& d S_{t} / S_{t}=r d t+\sqrt{\sigma^{2}+\left(1-\rho^{2}\right) \beta^{2} L_{t}^{2}} d W_{t}^{S, Q}+\rho \beta L_{t} d W_{t}^{L, Q}, \\
& d L_{t}=d\left(\phi \% L_{t}\right) d t+\xi d W_{t}^{L, Q}
\end{aligned}
$$

with

$d \sigma=\alpha+\omega$,

$\theta \% \frac{\alpha \theta}{\alpha+\omega}$,

$d W_{t}^{L, Q} d W_{t}^{S, Q}=0$,

where $\omega$ is a constant. There are six parameters to be determined for the SDEs: individual asset price volatility $\sigma$, correlation between individual asset return and market liquidity $\rho$, sensitivity of asset price to market liquidity $\beta$, mean reversion speed of market liquidity $\mathscr{k}$, long-run mean of market liquidity $\dot{\theta}$ 'and volatility of market liquidity $\xi$.

Now we can obtain the liquidity-adjusted derivative pricing model. We apply the FeynmanKac formula for the two-dimensional derivation, adopting $\mathrm{F}(\mathrm{S}, \mathrm{L}, \tau)$ to represent the value of futures contracts and $G(S, L, \tau)$ to be the value of American or European options when $S_{t}=S$ and $\mathrm{L}_{\mathrm{t}}=\mathrm{L}$. By using matrix multiplication and the Feynman-Kac formula, we develop two PDEs for the function $F(S, L, \tau)$ and $G(S, L, \tau)$ respectively: 


$$
\begin{aligned}
& \frac{\partial F}{\partial \tau}=r S \frac{\partial F}{\partial S}+d\left(\phi \theta^{\circ} L\right) \frac{\partial F}{\partial L}+\frac{1}{2} S^{2}\left(\sigma^{2}+\beta^{2} L^{2}\right) \frac{\partial^{2} F}{\partial S^{2}}+\frac{1}{2} \xi^{2} \frac{\partial^{2} F}{\partial L^{2}}+\rho \xi \beta L S \frac{\partial^{2} F}{\partial S \partial L} \\
& \frac{\partial G}{\partial \tau}=r S \frac{\partial G}{\partial S}+\&((2)-L) \frac{\partial G}{\partial L}+\frac{1}{2} S^{2}\left(\sigma^{2}+\beta^{2} L^{2}\right) \frac{\partial^{2} G}{\partial S^{2}}+\frac{1}{2} \xi^{2} \frac{\partial^{2} G}{\partial L^{2}}+\rho \xi \beta L S \frac{\partial^{2} G}{\partial S \partial L}-r G
\end{aligned}
$$

where $\tau=\mathrm{T}-\mathrm{t}$, is the time to maturity.

If $G(S, L, \tau)$ is the value of a prepayment option in a mortgage loan, then we can price any type of MBSs including CMOs and CDOs as long as the liquidity level of mortgage market can be effectively measured. There are two types of illiquidity measures, Amihud (2002) and Roll (1984), both can be used for mortgage markets. Amihud's illiquidity measure is based on price impact of trading volume, while Roll's illiquidity measure is a proxy for transaction cost. The higher measure indicates that the market is more illiquid. Though trading volume and transaction cost are proprietary data within each bank and banks usually develop their proprietary models for MBS pricing, banks can extend the model (2.10) to value prepayment options embedded in MBS products with input from their own proprietary data. Zhang (2007; 2009) ${ }^{1}$, and Zhang and Key (2010) develop various proprietary MBS valuation models without incorporating liquidity risk.

\section{Model Validation in Futures Markets}

We validate our model using the rather adequate data of the futures market. The reason for our approach is that, the mortgage data is proprietary. In order to validate our model, we compare our liquidity adjusted model to the benchmark model under the perfect liquidity market

\footnotetext{
${ }^{1}$ Zhang developed these models during his work at J.P. Morgan and Wells Fargo
} 
assumption.

\subsection{One-Factor Benchmark Model}

Many studies have documented the concept of "convenience yield" such as Gibson and Schwartz (1990) and Casassus and Collin-Dufresne (2005), and with particular focus on the oil futures (Dempster, Medova and Tang, 2012). Others, argue that the inclusion of convenience yield in the benchmark model will therefore reduce the modeling errors by making the theoretical prices strictly lower (Gibson and Schwartz, 1990; Heaney, 2002). As a result, in our benchmark model we include the convenience yield adjustment developed by Heaney (2002). He proposes that the convenience yield is the difference between two trading strategies, where $\delta=\mathrm{TS}\left(\mathrm{S}_{\mathrm{it}}, \mathrm{T}\right)-\mathrm{TS}\left(\mathrm{F}_{\mathrm{it}}, \mathrm{T}\right)$ and he defines the trading strategies as:

$$
\begin{aligned}
& T S\left(S_{i t}, T\right)=\ln \left\{\left[2+\frac{\sigma_{s}^{2}(T-t)}{2}\right] N\left[\frac{\sqrt{\sigma_{s}^{2}(T-t)}}{2}\right]+\sqrt{\frac{\sigma_{s}^{2}(T-t)}{2 \pi}} \exp \left[-\frac{\sigma_{s}^{2}(T-t)}{8}\right]\right\} \\
& T S\left(F_{i t}, T\right)=\ln \left\{\left[2+\frac{\sigma_{F}^{2}(T-t)}{2}\right] N\left[\frac{{\sqrt{\sigma_{F}^{2}(T-t)}}^{2}}{2}\right]+\sqrt{\frac{\sigma_{F}^{2}(T-t)}{2 \pi}} \exp \left[-\frac{\sigma_{F}^{2}(T-t)}{8}\right]\right\}
\end{aligned}
$$

Then, the SDE for the asset price with convenience yield adjustment becomes:

$$
\frac{d S_{t}}{S_{t}}=\left(u_{s}-\delta\right) d t+\sigma_{s} d W_{t}^{S^{\prime} P}
$$

where $\delta$ is the convenience yield, $\sigma_{\mathrm{s}}$ is the spot asset volatility and $\sigma_{\mathrm{F}}$ is the futures asset volatility. Then, the corresponding PDE for the futures price F becomes

$$
\frac{\partial F}{\partial \tau}=(r-\delta) S \frac{\partial F}{\partial S}+\frac{1}{2} S^{2} \sigma^{2} \frac{\partial^{2} F}{\partial S^{2}}
$$

Therefore, the benchmark model becomes

$\mathrm{F}=\mathrm{S}^{*} \exp ((\mathrm{r}-\delta) \tau)$

which is the original Black model adjusted with convenience yield as well as the solution to 
equation (3.3).

\subsection{Liquidity adjusted PDE Model for Futures Prices}

With convenience yield adjustment, the liquidity-adjusted SDEs equation (2.7) and (2.8) can be rewritten as:

$$
\begin{aligned}
& d S_{t} / S_{t}=(r-\delta) d t+\sqrt{\sigma_{s}^{2}+\left(1-\rho^{2}\right) \beta^{2} L_{t}^{2}} d W_{t}^{S, Q}+\rho \beta L_{t} d W_{t}^{L, Q} \\
& d L_{t}=\& /\left(\phi \ell-L_{t}\right) d t+\xi d W_{t}^{L, Q}
\end{aligned}
$$

where

$$
\begin{aligned}
& \&=\alpha+w \\
& \theta=\frac{\alpha \theta}{\alpha+w} \\
& d W_{t}^{L, Q} d W_{t}^{S, Q}=0
\end{aligned}
$$

where $\delta$ is the convenience yield and $\omega$ is a constant. Based on the derived stochastic processes, we can obtain the liquidity-adjusted PDE futures pricing with convenience yield as follows:

$$
\left.\frac{\partial F}{\partial \tau}=(r-\delta) S \frac{\partial F}{\partial S}+2 \% \phi^{\circ} L\right) \frac{\partial F}{\partial L}+\frac{1}{2} S^{2}\left(\sigma^{2}+\beta^{2} L^{2}\right) \frac{\partial^{2} F}{\partial S^{2}}+\frac{1}{2} \xi^{2} \frac{\partial^{2} F}{\partial L^{2}}+\rho \xi \beta L S \frac{\partial^{2} F}{\partial S \partial L}
$$

where $\tau=\mathrm{T}-\mathrm{t}$ is the time to maturity.

This PDE is then subject to the initial and boundary conditions. The initial condition is

$$
\mathrm{F}(\mathrm{S}, \mathrm{L}, 0)=\mathrm{S}
$$

The new PDE is also subject to the following boundary conditions taking convenience yield into account:

$$
\begin{aligned}
& \mathrm{F}(\mathrm{S}, 0, \tau)=\mathrm{Se}^{(\mathrm{r}-\delta) \tau}, \\
& \mathrm{F}(\mathrm{S}, \infty, \tau)=\mathrm{Se}^{(\mathrm{r}-\delta) \tau *} \mathrm{~d}, 0<\mathrm{d}<1 \\
& \mathrm{~F}(0, \mathrm{~L}, \tau)=0,
\end{aligned}
$$


$\mathrm{F}\left(\mathrm{S}_{\max }, \mathrm{L}, \tau\right)=\mathrm{S}_{\max } \mathrm{e}^{(\mathrm{r}-\delta) \tau}$

The first boundary condition (3.8) states that, when the market is perfectly liquid, futures prices are equal to the classical model values under the perfect market assumption discounted by convenience yield. The second boundary condition (3.9) states that, when the market is significantly illiquid, the theoretical futures prices must be discounted for that illiquidity and the boundary is also subject to convenience yield. The third boundary condition (3.10) states that, when spot prices are zero, theoretical futures prices are zero. The final boundary condition (3.11) states that, when spot prices are at maximum, the theoretical futures prices are the same as the benchmark price as if the market is sufficiently liquid because the asset price is at maximum.

\subsection{Data Description}

In order to validate our model, we utilize the data of both oil futures market and the gold futures market. Both oil futures and gold futures data come from New York Mercantile Exchange. The data provider is Thomson-Reuters Datastream.

Since we include an additional liquidity variable, it will inevitably increase the number of model parameters. The increasing number of parameters will then result in the in-sample fitting of the future prices and potentially improves the results. As a consequence, we will test the outof-sample performance in estimating futures market values over the period starting January 1 2015 and ending December 31 2015. The daily return of the oil futures and gold futures is presented in Fig 1 and Fig 2. Our data for both oil and gold futures cover the period from January 2014 to December 2015. We use the year 2014 as the estimation period to obtain the 
model parameters. Our out-of-sample test is carried out for the data of year 2015. Following Gibson and Schwartz (1990), we adopt the nearest futures market data as the input for the spot price as well as the current liquidity level and time to maturity. The model performance comparison covers different maturity groups over the same period, namely, 3-month futures, 3month futures, 5-month futures and 6-month futures.

In order to show the improvement and validation of our model, we use the classical model under the assumption of perfect liquidity as the benchmark model. We compare the theoretical values generated by the two models with the market price and demonstrate the accuracy of our model. We use two methods in Gibson and Schwartz (1990) and Harvey (1991) to exhibit the performance of the two models. The first method is called the mean pricing error (MPE) in dollars, which is measured as: $M P E=\frac{1}{N} \sum_{n=1}^{N}\left|\hat{F}_{n}-F_{n}\right|$. The other method is root mean squared error (RMSE) in dollars, namely, $R M S E=\sqrt{\frac{1}{N} \sum_{n=1}^{N}\left(\hat{F}_{n}-F_{n}\right)^{2}}$. In the two methods, $\mathrm{N}$ is the number of total observations; $\mathrm{F}_{\mathrm{n}}$ is the actual future price observed in the market and $\hat{F}_{n}$ is the theoretical future price estimated from the model. We demonstrate that our model has relatively small pricing errors under both measures of MPE and RMSE.

\subsection{Parameter Estimation Method}

In this paper, we use a unified and well-recognized liquidity measurement to validate our model. Marshall et al. (2012) test a large number of liquidity proxies for 19 commodities. They find that the Amihud liquidity proxy has the maximal correction ratio among all proxies and they strongly recommend researchers to use this proxy when modeling commodity liquidity. As a 
result, we use the proxy mentioned in Amihud (2002) to measure asset illiquidity and it takes the form:

$$
\operatorname{Amihud}_{t}=\frac{\left|R_{t}\right|}{\operatorname{Vol}_{t}}
$$

where $\mathrm{R}_{\mathrm{t}}$ is the asset return at time $\mathrm{t}$ and $\mathrm{Vol}_{\mathrm{t}}$ is the asset trading volume at time $\mathrm{t}$.

Intuitively, when trading volume is high, the amount of illiquidity measure is small and the asset is denoted to be more liquid. We scale asset illiquidity measure from 0 (maximal liquid) to 1 (maximal illiquid) for plotting graphs and adopt Amihud measure as the main illiquidity measure.

There are six parameters to be determined: long-run mean of the stochastic liquidity $\left(\mathscr{\theta}^{\prime}\right)$, mean reversion speed of the stochastic liquidity $(\alpha /)$, the volatility of asset return $(\sigma)$, the volatility of liquidity level $(\xi)$, the sensitivity of asset price towards market liquidity $(\beta)$ and the correlation between asset return and liquidity $(\rho)$. Regarding the volatility of asset return, they will take the usual form:

$$
\sigma=\sqrt{\frac{1}{N-1} \sum_{t=1}^{N}\left(R_{t}-E\left[R_{t}\right]\right)^{2}}
$$

which are also known as the sample standard deviation (Poon and Granger, 2003). Since the empirical return volatility contains components of fundamental return volatility and volatility of liquidity level, we decompose the empirical return volatility as $\sigma^{2}=\sigma_{s}^{2}+\beta^{2} L_{t}^{2}$, where $\sigma$ is the empirical return volatility. Moreover, $\beta$ measures the individual sensitivity of the asset against the market liquidity and $\beta$ can be set equal to 1 since in our model, there is only one common asset trading in the market.

After collecting the data, we then test the mean-reverting property of the market liquidity by 
regressing the Amihud measure in AR (1) process since the discretization of the mean-reverting process is AR (1) process. It takes the general form: $L_{t}=\varphi_{1}+\varphi_{2} L_{t-1}+\varepsilon_{t}$ and if the absolute value of coefficient $\varphi_{2}$ is less than 1 , then the process will be a mean-reverting process. The commonly used unit root test is the Augmented Dickey-Fuller (ADF) test. If the time series does not have a unit root, then the process is probably mean-reverting since the process without a unit root is considered as a stationary process (Wu, 2000; Narayan and Prasad, 2007). The results for Amihud measure with one and two lags in the oil market and gold market are strongly significant to reject the null hypothesis. From the results, we can see that our liquidity measure has no unit root and is a mean-reverting process, which supports our argument that asset liquidity is mean-reverting.

Since the process is mean-reverting, it has the long-run mean: $\tilde{\theta}=\frac{\varphi_{1}}{1-\varphi_{2}}$. Then, the mean reversion speed can be estimated from the following stochastic process (Balvers et al., 2000): $L_{t}-L_{t-1}=\varphi_{3}+\varphi_{4}\left(\theta-L_{t-1}\right)+\varepsilon_{t}$, where $\varphi_{4}$ is the mean reversion speed and $0<\varphi_{4}<1 . \varphi_{1}$ and $\varphi_{3}$ are positive constants and $\varepsilon_{\mathrm{t}}$ is the noise term with unconditional mean of zero. Since the model $L_{t}=\varphi_{1}+\varphi_{2} L_{t-1}+\varepsilon_{t}$ is equivalent to $L_{t}-L_{t-1}=\varphi_{1}+\left(\varphi_{2}-1\right) L_{t-1}+\varepsilon_{t}$, and $\varphi_{2}$ is the coefficient of the AR(1) process, we find that the $\varphi_{4}=1-\varphi_{2}$ and $\& / \sigma=\varphi_{4}$.

Moreover, the volatility of liquidity is usually measured as the volatility of liquidity shocks (P'astor and Stambaugh, 2003; Sadka, 2006). The shock of liquidity is usually estimated by the residuals of the liquidity autoregression process. As a result, we estimate the volatility as follows. Firstly, we discretize the mean-reverting process of liquidity as $L_{t}-L_{t-1}=8 /\left(8-L_{t-1}\right)+\varepsilon_{t}$ and we set $\mathrm{dt}=1$. Then, the residual can be known as $\varepsilon_{t}=L_{t}-L_{t-1}-d /\left(\phi \theta-L_{t-1}\right)$. 
Then, we plug in the parameters and find the liquidity volatility $\xi=\sqrt{\frac{1}{N-1} \sum_{t=1}^{N}\left(\varepsilon_{t}-E\left[\varepsilon_{t}\right]\right)^{2}}$. Finally, the correlation between asset return and asset liquidity volatility, which can be estimated as: $\rho=\frac{\operatorname{Cov}\left(R_{t}, \varepsilon_{t}\right)}{\xi \sigma}$.

In addition, we use annual 6-month T-Bill rate as the risk-free rate and we set the risk-free rate at $0.5 \%$ for the year 2015 . As we obtain the parameters of the two stochastic processes along with the risk-free rate, we can use the new model to estimate the oil and gold futures values.

\subsection{Model Performance in Oil Futures Market}

In this section, we conduct a model accuracy test for the oil futures market validation. The benchmark model is described in equation (3.3) with the solution of $\mathrm{F}=\mathrm{S}^{*} \exp ((\mathrm{r}-\delta) \tau)$. The new model we develop is described in equation (3.6), with the initial condition of equation (3.7) and boundary conditions of equations (3.8) - (3.11). For the two models, we input the spot price, the current liquidity level and the time to maturity to predict the oil futures values of four different maturity groups, namely, 3-month, 3-month, 5-month, 6-month. After we obtain theoretical values from the two models, we compare them with the observed future market values. The out-of-sample pricing performance of oil futures for all maturity groups is presented in Table 3-1 and Table 3-2 for MPE and RMSE respectively. We find that our model effectively eliminates the pricing errors compared to the traditional futures pricing model for both evaluation criteria, namely, MPE and RMSE.

The performance of liquidity adjusted (LA) model slightly surpasses the non-liquidity 
adjusted (NLA) model regarding the two pricing errors evaluation criteria. From the two tables (Table 3-1 and Table 3-2), we can observe that the means of MPE and RMSE for LA model are smaller than those of the NLA model. It indicates that in average the LA model can provide more accurate results compared to the NLA model. Moreover, the standard deviations of pricing errors for the LA model are lesser than those of the NLA model. The results show that the LA model is more stable than the NLA model for the oil futures pricing.

Following Feng et al. (2014), we use the improvement rate to further illustrate the performance differences between the two models, we report the improvement rates in the last column of the two tables (Table 3-1 and Table 3-2). The improvement rate is defined as the absolute value of the difference between the mean pricing errors of LA and NLA models divided by those of the benchmark model, namely, the NLA model. The improvement rate for oil futures pricing in MPE varies between $12.4 \%$ to $17.9 \%$ for different maturity groups, which might suggest that the LA model has reduced the errors about 15\% compared to the benchmark model. We also adopt the t-test of two groups of MPE. Table 3-1, shows that all p-values are statistically significant, which indicates that errors estimated from LA model are significantly smaller than the NLA errors. The errors estimated from the two models are presented in Fig 3 for oil futures valuation. It is obvious from the graph that the red line, which exhibits the errors from LA model is generally below the black line that exhibits the errors from NLA model.

\subsection{Model Performance in Gold Futures Market}

We conduct a model accuracy test for the gold futures validation in this section as a robustness check for our results. With regard to the gold futures pricing, the performance of LA model 
overwhelmingly outperforms the NLA model for two pricing error evaluation criteria. Table 33 and Table 3-4, show that the means of MPE and RMSE are far smaller than those of the NLA model. The LA model provides far more accurate results compared to the NLA model. Moreover, the standard deviations of pricing errors for the LA model are smaller than those of the NLA model. The error terms for LA model are quite stable for the gold futures estimations. Similarly, we compare the results from the two models by the improvement rate. Compared to the results obtained for oil futures data, the results for gold futures data are much better. Table 3-3, demonstrates that the improvement rate is as high as $50 \%$ except for the 6 -month gold futures estimation. The mean of errors for NLA model 6-month futures estimation is nearly half of its results for 3-month and 3-month futures. Fig 4, illustrates that for 3-month and 3month gold futures estimations, the gaps between two error lines are more diverged. In contrast, the gaps are much smaller for 5-month and 6-month gold futures estimations.

One possible explanation for more accurate results obtained in gold futures is that gold price was more stable than oil price in the year 2015. Fig 5, illustrates that the spot price of oil futures is much more volatile than the spot price of gold futures. As a result, the volatile spot oil price might impede our model accuracy since volatile prices could be difficult for a stable model to predict and estimate.

\subsection{Liquidity and Maturity Term Structure Coupling Effects}

Using the theoretical PDE solutions we have obtained from equation (3.6), we investigate a coupling effect of illiquidity discounting and futures maturities. In order to exhibit the discount factor more visibly, we define an adjustment ratio, which is AdjustmentRatio $=\frac{F(S, L, \tau)}{S e^{(r-\delta) \tau}}$. 
This ratio represents the difference between theoretical values implied by our model and theoretical values implied by the benchmark model (Black's classical model). Fig 6 shows the adjustment ratio against asset liquidity. It is seen that, when the market is maximally liquid, the theoretical values from two models are almost identical (adjustment ratio=1). On the other side, when the market becomes more illiquid, the difference between two models enlarges. When the market is perfect illiquid, the asset value with liquidity factor is around $10 \%$ of the classical model, which is the discount factor $10 \%$. The downward sloping curve is consistent with the asset bearing higher liquidity risk requiring higher return, thus a lower market price. Furthermore, the black line presents the 3-month futures prices and the blue line presents the 9-month futures prices. The blue line is steeper than the black line, which suggests that the liquidity effects are more noticeable for the long maturity futures. This is in accord with empirical evidence from the bond market, where it is found that a liquidity premium increases with the maturity (Amihud and Mendelson, 1991; Fontaine and Garcia, 2012).

In order to present the relationship more clearly, in Fig 7 we plot the adjustment ratio against maturity ( 0 represents now and 1 represents a year). It is seen that the adjustment ratio is downward sloping and gradually decreases as the maturity increases. This also indicates that liquidity is related to maturity, and long maturity assets generally have larger liquidity effects and will be discounted more than short maturity assets. When the assets are more illiquid, prices are adjusted downward in greater degree compared to standard no arbitrage prices. Fig 8 shows that the adjustment ratio against price with a fixed maturity, and the curve is generally flat. The liquidity adjustment ratios seem independent of spot prices for a fixed maturity. To sum up, the adjustment ratio depends on the futures maturities and liquidity level. Futures with longer 
maturity imply deeper adjustment for a fixed spot liquidity level. Additionally, futures with more illiquid spot trading also have deeper adjustment for a fixed spot price.

\section{Conclusions and Policy Implications}

The study of an explicit role of liquidity risk has become the focus of much financial research following the virtual collapse of LTCM in 1998. A factor of liquidity does appear to matter for derivative prices as well, including futures, options and MBS products. However, existing derivative pricing models are few and far between in the literature and have also been limited to pricing liquidity risk for European derivatives only. As a consequence, we develop a general liquidity-adjusted derivative pricing model, which can price derivatives of a wide variety including American options, MBSs and commodity futures contracts.

The validation of our model is carried out for futures markets for which data is widely available. In particular, we conducted model performance tests for oil and gold futures markets, which play a prominent role in financial markets. In order to validate our model, we empirically compare the liquidity adjusted model (LA) and the benchmark model without liquidity adjustment (NLA) in their accuracy of futures pricing. The LA model surpasses the NLA model, in light of the fact that it provides lower but more precise theoretical values than the NLA model when compared to actual market futures data. The improvement rate of our model compared to the benchmark model for the oil futures valuation is about $15 \%$ for the out-of-sample test. Furthermore, the improvement rate turns out to be even more pronounced for the gold futures valuation, for which we obtain a rate of 50\%. Comparing the performance of our model for the two commodity futures markets, the LA model performs much better in the gold futures market, 
which might indicate that gold futures prices are more sensitive to liquidity risk.

Finally, we also carry out a theoretical study on liquidity effects on futures prices coupled with maturity. We find that, when the assets are more illiquid, futures prices are adjusted downward to a greater degree when compared to standard no-arbitrage futures prices. Such adjustment appears to occur independently of spot prices for a fixed maturity. The illiquidity adjustment depends on the futures maturities; if deferred futures are less liquid than nearby futures then longer maturity implies a deeper degree of adjustment for a fixed spot liquidity level.

Our new model carries important implications for policy design aimed at regulating liquidity risks for derivative markets including both futures and option markets. Because leverage is embedded in derivative trading, any financial risk including liquidity risk can be magnified by a substantial multiple. Therefore, financial innovations in derivatives must be carefully regulated with effective policies and mechanisms to monitor their liquidity risk and to develop and test robust pricing models with can accurately capture liquidity risk.

\section{Acknowledgements:}

The authors would like to thank Professor Robert Webb for his comments which have helped to improve the paper. This work is supported by Ningbo-CASS collaborative grant NZKT201701.

\section{REFERENCE}

Acharya, V., and L., Pedersen, 2005, Asset pricing with liquidity risk, Journal of Financial Economics 77, 375-410.

Amihud, Y., and H., Mendelson, 1991, Liquidity, maturity, and the yields on US Treasury securities, The Journal of Finance 46, 1411-1425. 
Amihud, Y., 2002, Illiquidity and stock returns: Cross-section and time-series effects, Journal of Financial Markets 5, 31-56.

Bingham, N., and R., Kiesel, 1998, Risk-Neutral Valuation: Pricing and Hedging of Financial Derivatives, New York: Springer.

Bongaerts, D., F., De Jong, and J., Driessen, 2011, Derivative pricing with liquidity risk: Theory and evidence from the credit default swap market, The Journal of Finance 66, 203-240.

Brunetti, C., and A., Caldarera, 2006, Asset prices and asset correlations in illiquid markets, In Computing in Economics and Finance 2006 (No. 331), Society for Computational Economics.

Brunnermeier, M. K., and Y., Sannikov, 2014, A macroeconomic model with a financial sector, American Economic Review 104, 379-421.

Calvo, G., 2012, Financial crises and liquidity shocks a bank-run perspective, European Economic Review 56, 317-326.

Casassus, J., and P., Collin-Dufresne, 2005, Stochastic convenience yield implied from commodity futures and interest rates, The Journal of Finance 60, 2283-2331.

Chou, R. K., S. L., Chung, Y., J. Hsiao, and Y., H. Wang, 2011, The impact of liquidity on option prices, Journal of Futures Markets 31, 1116-1141.

Cornett, M. M., J. J., McNutt, P. E., Strahan, and H., Tehranian, 2011, Liquidity risk management and credit supply in the financial crisis, Journal of Financial Economics 101, 297-312.

Dempster, M. A. H., E., Medova, and K., Tang, 2012, Determinants of oil futures prices and convenience yields, Quantitative Finance 12, 1795-1809.

Ewing, B. T., and F., Malik, 2013, Volatility transmission between gold and oil futures under structural breaks, International Review of Economics \& Finance 25, 113-121.

Feng, S.-P., M.-W., Hung, and Y.-H., Wang, 2014, Option pricing with stochastic liquidity risk: Theory and evidence, Journal of Financial Markets 18, 77-95.

Fontaine, J. S., and R., Garcia, 2012, Bond liquidity premia, Review of Financial Studies 25, 1207-1254.

Frino, A., Mollica, V., \& Webb, R. I., 2014, The impact of co-location of securities exchanges' and traders' computer servers on market liquidity, Journal of Futures Markets 34, 20-33.

Gibson, R., and E. S., Schwartz, 1990, Stochastic convenience yield and the pricing of oil contingent claims, The Journal of Finance 45, 959-976.

Grudnitski, G., and Osburn, L. 1993, Forecasting S\&P and gold futures prices: An application of neural networks, Journal of Futures Markets 13, 631-643.

Heaney, R., 2002, Approximation for convenience yield in commodity futures pricing, Journal of Futures Markets 22, 1005-1017.

Kyle, A., 1985, Continuous auctions and insider trading, Econometrica 53, 1315-1335.

Li, G., and C., Zhang, 2011, Why are derivative warrants more expensive than options? An empirical study, Journal of Financial and Quantitative Analysis 46, 275-297.

Liu, W., 2006, A liquidity-augmented capital asset pricing model, Journal of Financial Economics 82, 631-671.

Longstaff, F., and E., Schwartz, 2001, Valuing American options by simulation: a simple leastsquares approach, Review of Financial Studies 14, 113-147. 
Mancini, L., A., Ranaldo, and J., Wrampelmeyer, 2013, Liquidity in the foreign exchange market: Measurement, commonality, and risk premiums, The Journal of Finance 68, 1805-1841.

Marshall, B., N., Nguyen, and N., Visa ltanachoti, 2011, Commodity liquidity measurement and transaction costs, Review of Financial Studies 25, 599-638.

Marshall, B., N., Nguyen, and N., Visa ltanachoti, 2013, Liquidity commonality in commodities, Journal of Banking \& Finance 37, 11-20.

Melvin, M., and J., Sultan,1990, South African political unrest, oil prices, and the time varying risk premium in the gold futures market, Journal of Futures Markets 10, 103-111.

Narayan, P., and A., Prasad, 2007, Mean reversion in stock prices: New evidence from panel unit root tests for seventeen European countries, Economics Bulletin 3, 1-6.

P'astor, L., and R., Stambaugh, 2003, Liquidity Risk and Expected Stock Returns, Journal of Political Economy 113, 642-685.

Poon, S.-H., and C., Granger, 2003, Forecasting volatility in financial markets: A review, Journal of Economic Literature 41, 478-539.

Roll, R., 1984, A simple implicit measure of the effective bid-ask spread in an efficient market, The Journal of Finance 39, 1127-1139.

Sadka, R., 2006, Momentum and post-earnings-announcement drift anomalies: The role of liquidity risk, Journal of Financial Economics 80, 309-349.

Souček, M., 2013, Crude oil, equity and gold futures open interest co-movements, Energy Economics 40, 306-315.

Webb, R. I., Ryu, D., Ryu, D., \& Han, J., 2016, The price impact of futures trades and their intraday seasonality, Emerging Markets Review 26, 80-98.

$\mathrm{Wu}$, J. L., 2000, Mean reversion of the current account: Evidence from the panel data unit-root test, Economics Letters 66, 215-222.

Zhang, Y., Ding, S., and Scheffel, E., 2018, Policy Impact on Volatility Dynamics in Commodity Futures Markets: Evidence from China, Journal of Futures Markets 38, 12271245 .

Zhang, Y., Ding, S., 2018, The Return and Volatility Co-movement in Commodity Futures Markets: The Effects of Liquidity Risk, Quantitative Finance 18, 1471-1486. 


\begin{tabular}{|c|c|c|c|c|c|c|}
\hline \multirow[b]{2}{*}{ Maturity } & \multicolumn{2}{|c|}{ LA Model } & \multicolumn{2}{|c|}{ NLA Model } & \multirow{2}{*}{$\begin{array}{l}\text { Improvement } \\
\text { rate }(\%)\end{array}$} & \multirow{2}{*}{$\begin{array}{l}\text { P-value } \\
\text { for } \\
\text { t-test }\end{array}$} \\
\hline & Mean & Std Dev & Mean & Std Dev & & \\
\hline 3-Month & 1.36 & 0.82 & 1.66 & 0.84 & 17.9 & 0 \\
\hline 4-Month & 2.10 & 1.10 & 2.40 & 1.11 & 12.4 & 0 \\
\hline 5-Month & 2.57 & 1.31 & 3.07 & 1.34 & 16.2 & 0 \\
\hline 6-Month & 3.11 & 1.51 & 3.67 & 1.53 & 14.9 & 0 \\
\hline
\end{tabular}

Table 3-1: MPE for Different Maturity Groups of Oil Futures 


\begin{tabular}{clllllll}
\hline \multirow{2}{*}{ Maturity } & \multicolumn{2}{l}{ LA Model } & & \multicolumn{2}{l}{ NLA Model } & Improvement rate \\
\cline { 2 - 3 } & Mean & Std Dev & & Mean & Std Dev & $(\%)$ \\
\hline 3-Month & 1.60 & 2.91 & & 1.86 & 3.39 & 13.9 \\
4-Month & 2.38 & 5.69 & & 2.64 & 6.41 & 10.1 \\
5-Month & 2.89 & 8.32 & & 3.35 & 9.62 & 13.4 \\
6-Month & 3.46 & 11.23 & & 3.97 & 12.86 & 12.6 \\
\hline
\end{tabular}

Table 3-2: RMSE for Different Maturity Groups of Oil Futures

John Wiley \& Sons, Inc. 


\begin{tabular}{clllllll}
\hline \multirow{2}{*}{ Maturity } & \multicolumn{2}{l}{ LA Model } & & \multicolumn{2}{l}{ NLA Model } & Improvement rate \\
\cline { 2 - 3 } & Mean & Std Dev & & Mean & Std Dev & $\begin{array}{l}\text { P-value } \\
\text { for } \\
\text { t-test }\end{array}$ \\
\hline 3-Month & 0.51 & 0.24 & 1.18 & 0.25 & 56.3 & 0 \\
4-Month & 0.48 & 0.38 & & 1.07 & 0.39 & 54.9 & 0 \\
5-Month & 0.38 & 0.31 & & 0.75 & 0.42 & 49.3 & 0 \\
6-Month & 0.44 & 0.35 & & 0.55 & 0.36 & 18.2 & 0 \\
\hline
\end{tabular}

Table 3-3: MPE for Different Maturity Groups of Gold Futures 


\begin{tabular}{cllllll}
\hline \multirow{2}{*}{ Maturity } & \multicolumn{2}{l}{ LA Model } & & \multicolumn{2}{c}{ NLA Model } & Improvement rate \\
\cline { 2 - 3 } & Mean & Std Dev & & Mean & Std Dev & $(\%)$ \\
\hline 3-Month & 0.57 & 0.37 & & 1.20 & 0.62 & 52.4 \\
4-Month & 0.61 & 0.54 & & 1.14 & 0.97 & 46.1 \\
5-Month & 0.49 & 0.37 & & 0.86 & 0.76 & 42.6 \\
6-Month & 0.56 & 0.45 & & 0.65 & 0.50 & 13.3 \\
\hline
\end{tabular}

Table 3-4: RMSE for Different Maturity Groups of Gold Futures 


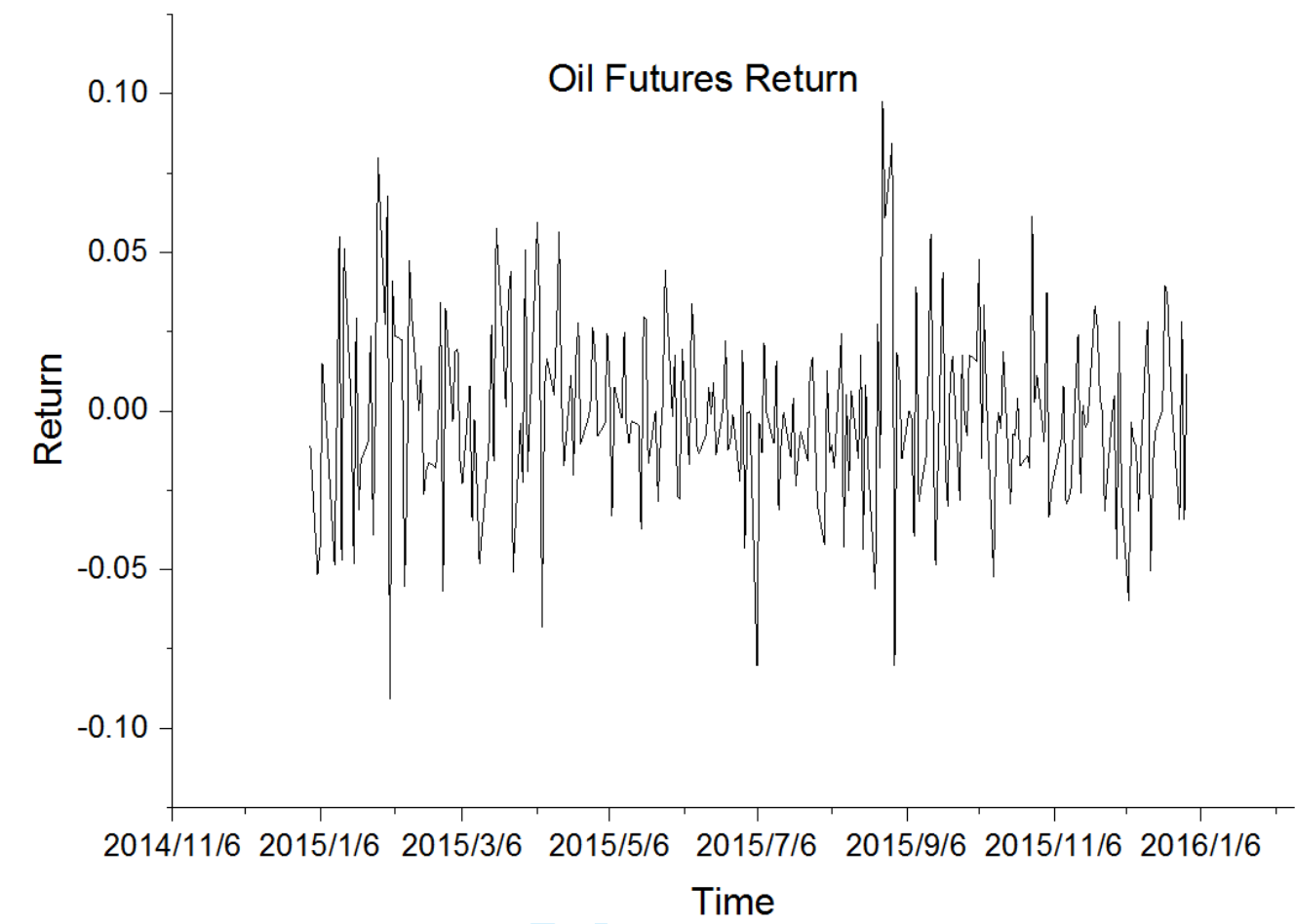

Fig 1: Oil futures return for the year 2015 


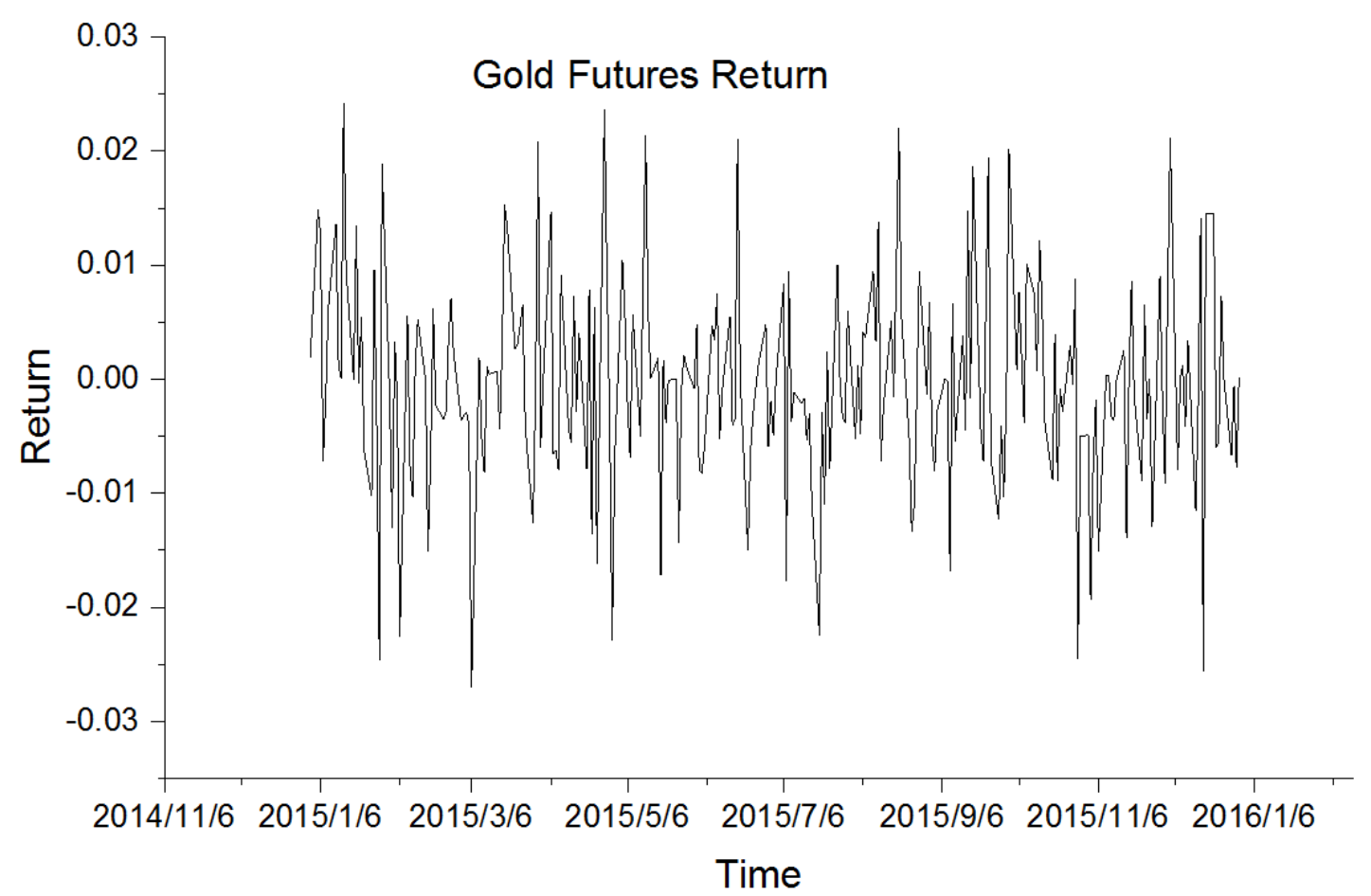

Fig 2: Gold futures return for the year 2015 


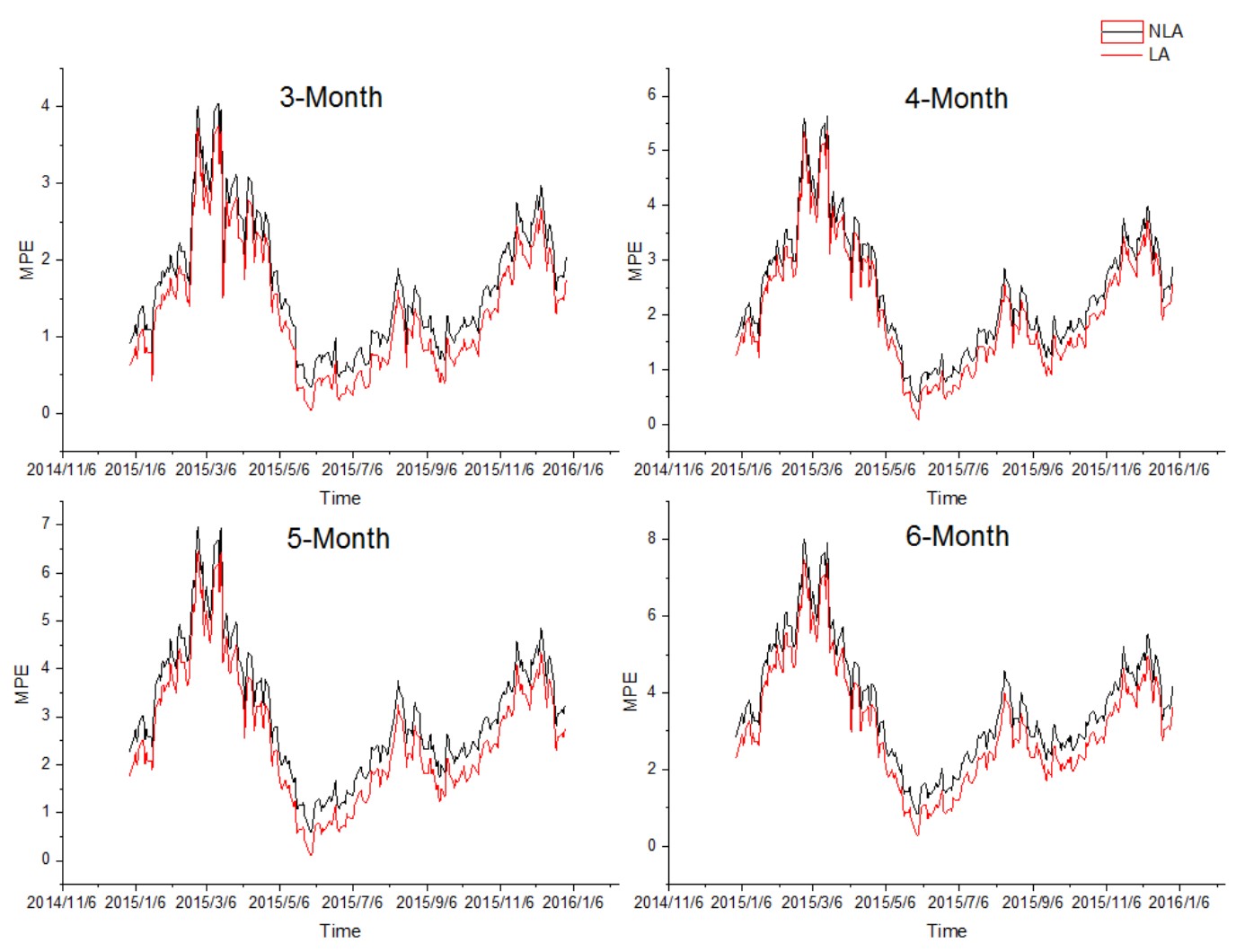

Fig 3: MPE comparison for two models in 2015 (For oil futures) 


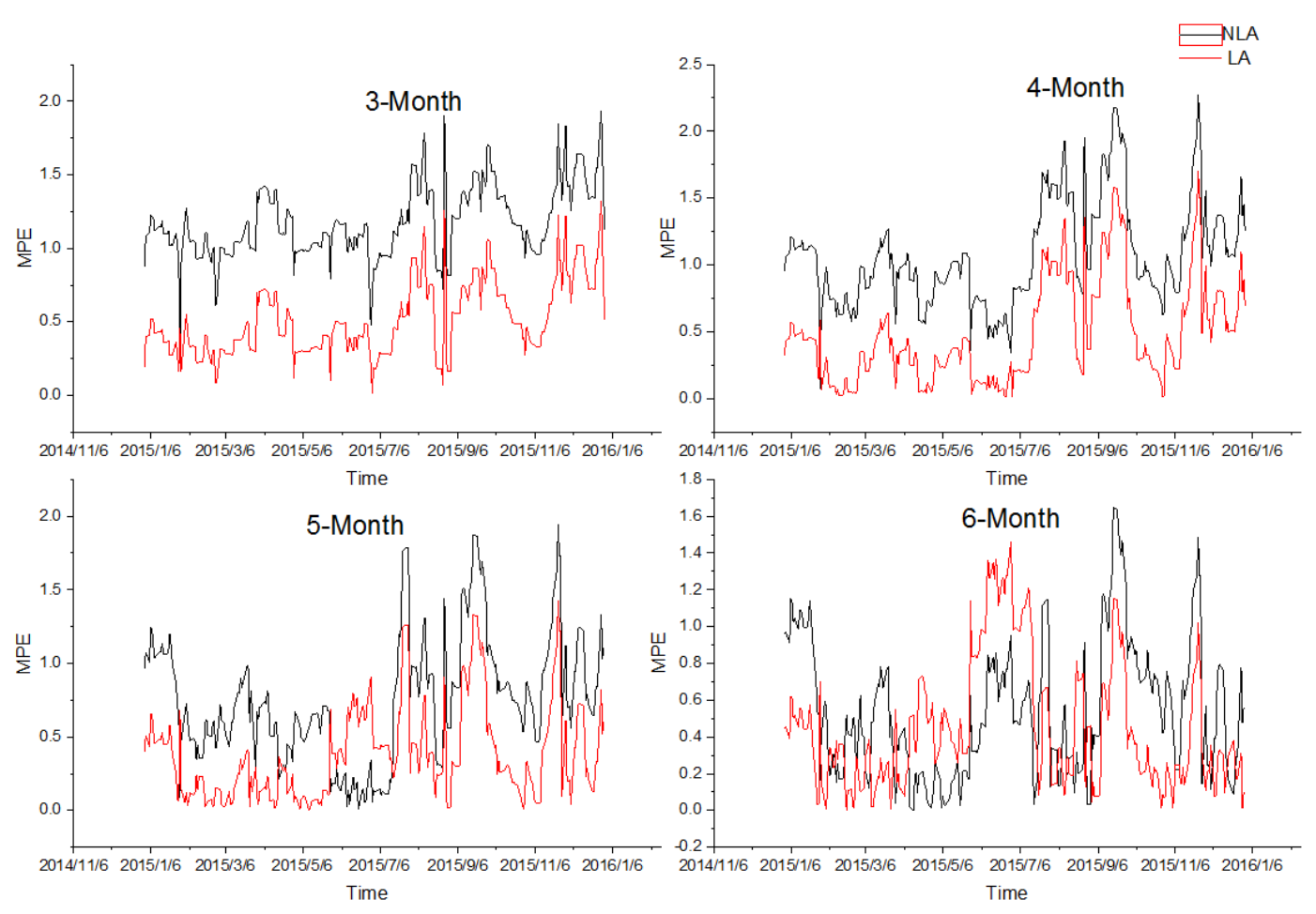

Fig 4: MPE Comparison for two models in 2015 (For gold futures) 


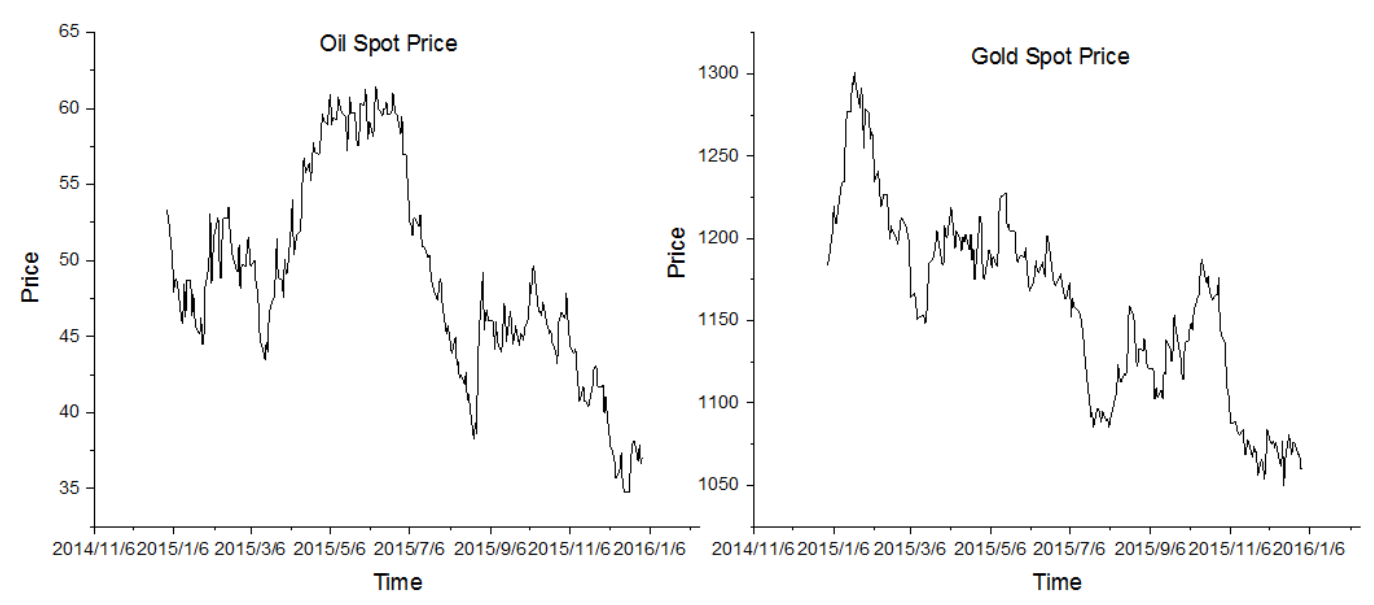

Fig 5: Spot price for both oil futures and gold futures 


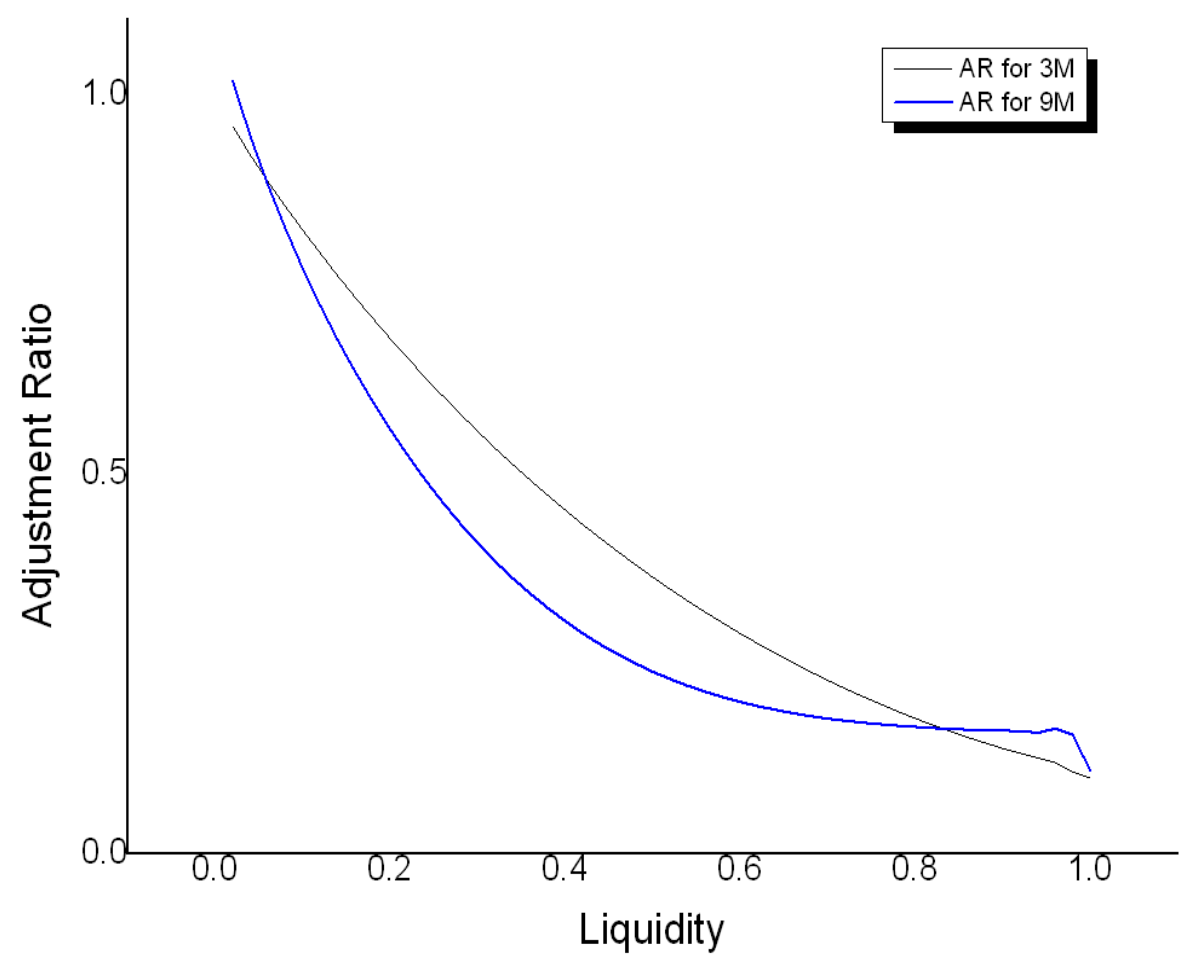

Fig 6: The plot of liquidity against adjustment ratio (AR) which is defined as the ratio of the price from the liquidity adjusted model to the price from the bench mark model without liquidity adjustment for futures with 3 months and 9 month maturities.

(The spot price is fixed at $\$ 100$ ) 


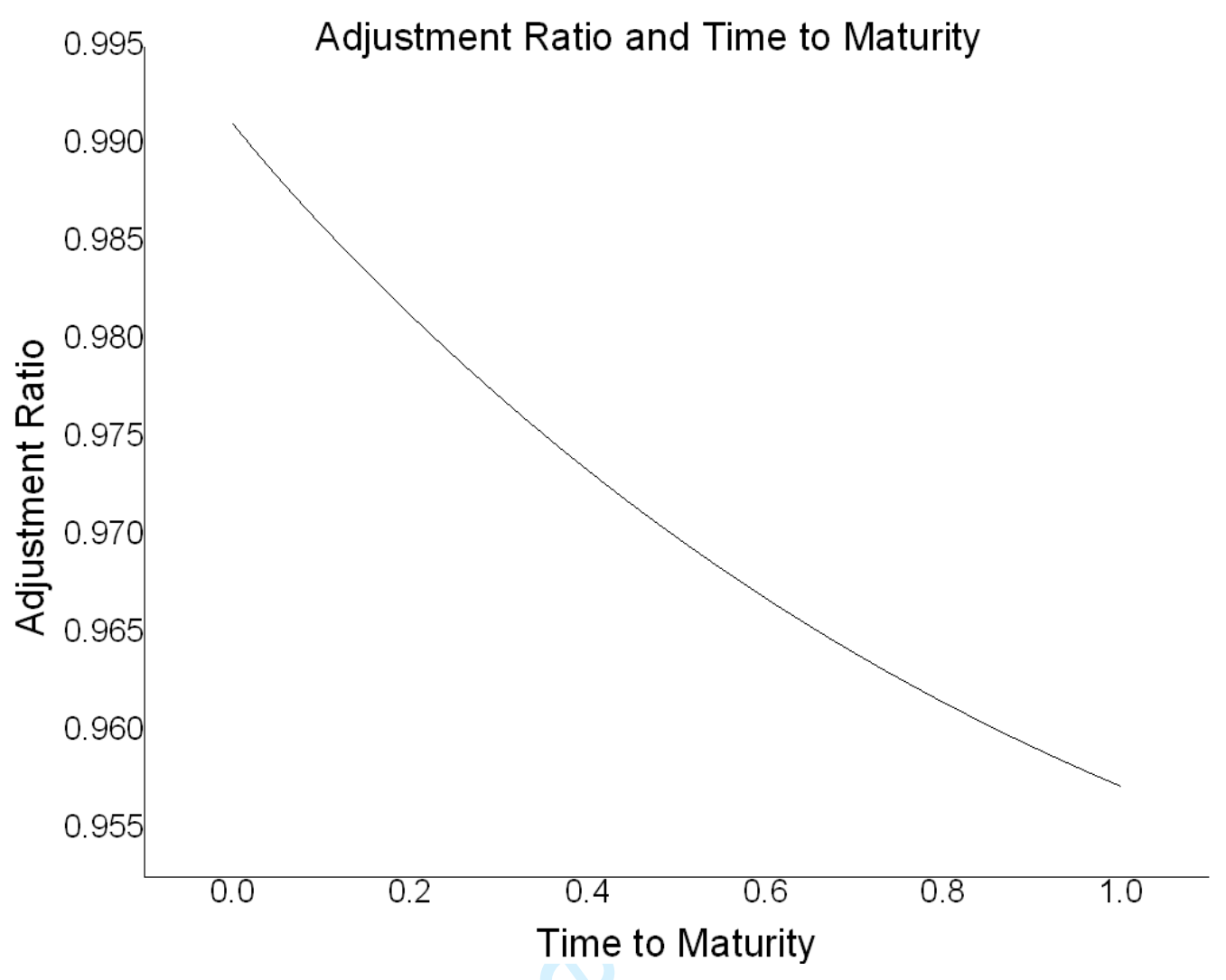

Fig 7: Plot of time to maturity against adjustment ratio (The spot price is fixed at $\$ 100$ and liquidity level is fixed at 1\%) 


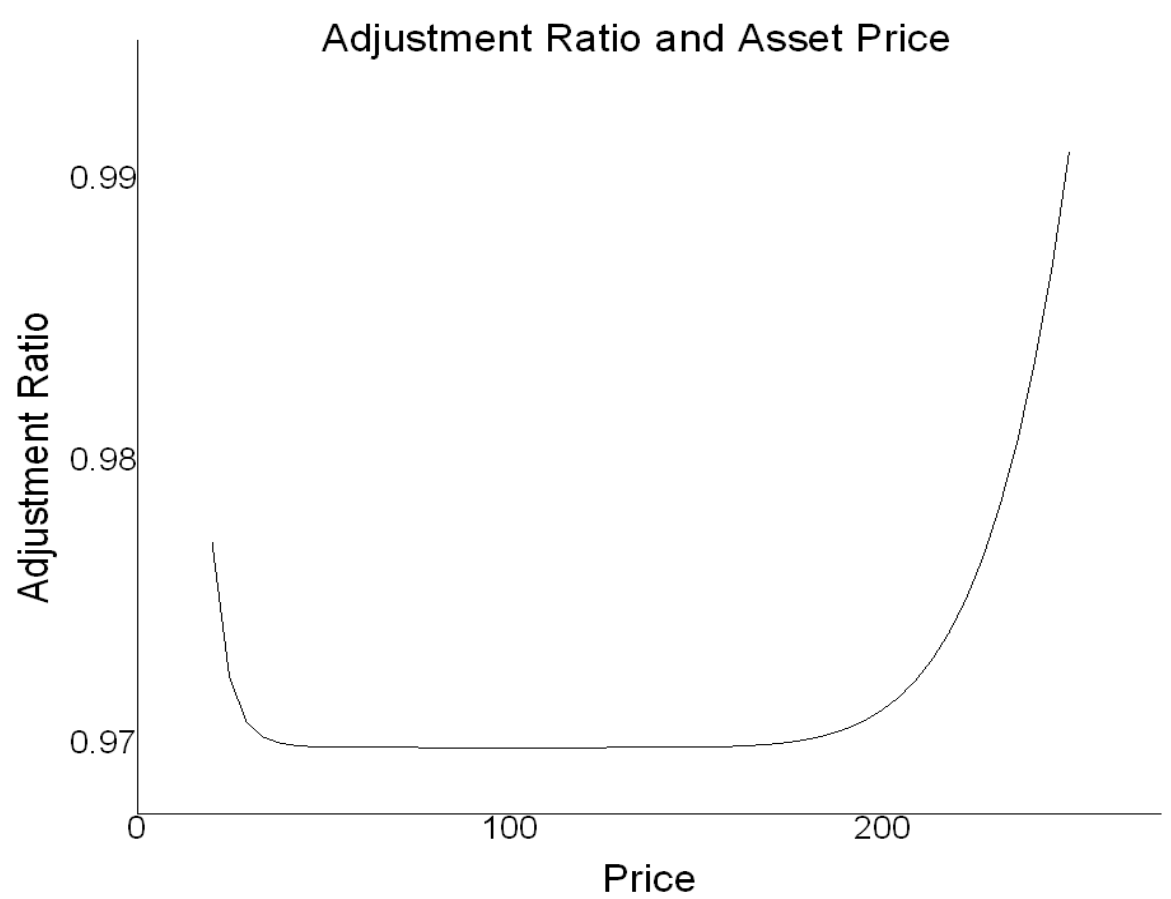

Fig 8: Plot of spot price against adjustment ratio

(The time to maturity is fixed at 6-month and liquidity level is fixed at 1\%) 